\title{
Load capacity prediction of in-service timber utility poles considering wind load
}

\author{
Yang $\mathrm{Yu}^{1}$, Jianchun $\mathrm{Li}^{1^{*}}$, Ning Yan ${ }^{1}$, Ulrike Dackermann ${ }^{1}$ and Bijan Samali ${ }^{2}$ \\ ${ }^{1}$ School of Civil and Environmental Engineering, University of Technology Sydney, NSW 2007, Australia \\ ${ }^{2}$ Institute for Infrastructure Engineering, Western Sydney University, NSW 2751, Australia \\ *Corresponding author: jianchun.li@uts.edu.au
}

\begin{abstract}
This paper presents a numerical investigation on the influence of different types of damage to the load capacity of in-service timber utility poles. Current design codes do not highlight a pole's strength performance due to different types of damage. However, damages typically found in ageing timber poles, such as damage due to fungus or termite attack, have very different characteristics and result in various effects on the strength properties of timber poles. Hence, the presented study investigates the influence of typical common types of damage to the strength properties and load capacities of timber utility poles. The study considers the damage type, location and severity. Wind load is considered as critical load due to the practical issue. The research shows that external damages at ground level significantly affect the load capacity of a timber pole. While internal damage, such as termite nests, has less influence on the load capacity regardless of the damage location and severity.
\end{abstract}

\section{Keywords}

Timber utility poles, load capacity prediction, numerical modelling, strength analysis

\section{Introduction}

Utility poles made of timber are traditionally utilised all over the world because they are relatively low in cost and environmentally friendly. Especially in Australia, timber utility poles represent a significant part of the country's infrastructure for power distribution and communication networks. There are almost seven million timber poles in the current network in Australia, and among them, five million poles are used for power and communication supply [1].

Although timber poles are initially strong in strength, over their designed service life, they often experience deterioration and decay of varying levels due to fungus or termite attacks. Such deterioration and decay may significantly affect their load capacity and may lead to failure with potentially serious consequences such as loss of life and high economic cost. To quantify the load capacity or strength of timber utility poles, limit-state design procedures were suggested by Crews and Horrigan [2]. A limit state is formally defined by the description of a condition for which a particular structural member or an entire structure fails to perform the function that is expected of it. Ultimate strength typically represents the collapse of the structure due to loss of structural stiffness and strength. The limit-states determined for a particular structure are used in the application of reliability-based design procedures and are aimed at achieving an acceptable risk of the structure failing for a particular loading condition [3]. The structure shall be designed to withstand safely all loads likely to act on it throughout its life and satisfy the serviceability requirements. It means that the probability of a limit state being reached during its lifetime should be very low. For the limit state design of timber utility poles, limit-states are the limiting conditions beyond which a pole ceases to fulfil its intended function, and are calculated using a load and resistance format that separates the effects of component strengths and their variability from the effects of external loadings and their uncertainty.

Timber poles are typically used to provide support for gravity loads and resistance against lateral forces. The most common lateral forces acting on pole structure are wind loads. Following existing standards, load capacity design for timber structures is based on modifying the characteristic capacities by factors appropriate to the service condition as well as the material property type. The 
design capacity in bending of round timbers, such as poles or piles, for the strength limit state is defined in Australia Standard AS1720.1 [4]. While this standard covers the general design capacity, it does not consider the influence of the damage type of a timber pole on its strength performance. Indeed, the effects of different types of damage on the load capacity of timber utility poles are distinctly different.

For timber poles used in power and communication networks, the poles have different types and quantities of cables attached on their top. As a result, wind loads acting on these cables have to be considered in the load capacity design. The cables have a uniformly distributed mass along their length and are very sensitive to wind loading. In general, consideration of maximum wind load cases acting along the cable length as well as normal to the cable length is necessary for load capacity design. For network distribution applications, at the end of a distribution network or if cables are attached to the poles at certain angles, the stays of the poles are designed to take the full load and not just the portion by which the load exceeds the pole capacity. The purpose of this design is to avoid the collapse along the cables distribution. In this situation, the wind loads normal to the cable length are more likely to cause the utility poles to collapse.

Based on the limitations of current standards and code of practice, this paper investigates the influence of different damage types, typically found in timber poles, on their load capacity and strength. Wind loads acting normal to the cable length are used in the design analysis. Numerical models of timber poles inflicted with various types of damage are used to validate this study. The paper is organised as follows: in the succeeding section, the load capacity of timber poles under wind load is theoretically analysed. Section 3 discusses the influences of damage type and severity on the poles strength. And finally, a conclusion is drawn in Section 4 that summarises this work.

\section{Design of wind load}

In the Ausgrid standard, for round timber poles, a design wind pressure of $1.3 \mathrm{kPa}$ is adopted based on the practical experience. The wind load on a round pole, resolved to its tip, is given by:

$$
F_{T}=0.5 h D_{a v} P
$$

where $F_{T}$ is the tip load due to wind load on pole, $h$ denotes the pole height above ground, $P$ is the design wind pressure on pole and $D_{a v}$ represent the mean diameter of the pole.

Ausgrid generally utilizes CCA-treated (a chemical timber preservative coating containing chromium, copper and arsenic) timber poles for distribution lines and there are some typical types of length used for different applications, shown in Table 1.

Table 1 Typical length of poles used in Ausgrid

\begin{tabular}{cc}
\hline Length $(\mathrm{m})$ & Typical application \\
\hline 10 & Stay poles \\
11.5 & LV poles \\
12 & $11 \mathrm{kV}$ or $22 \mathrm{kV}$ poles \\
14 & Transformer, recloser, regulator, or HV UGOH poles \\
\hline
\end{tabular}

In this study, the utility poles used for intermediate in-line sites are investigated, lighter poles are considered in this situation and can be set to $12 \mathrm{~m}$ long with average diameter of $0.315 \mathrm{~m}$. Normally the embedment length of a pole is $1.5 \mathrm{~m}$ to $2 \mathrm{~m}$, so the height above ground level can be considered as $10 \mathrm{~m}$. The tip load due to the wind load on the pole can be calculated which is $1.95 \mathrm{kN}$.

After considering the wind load directly acting on timber poles, wind load influencing the poles through conductors should be taken into account. Transverse wind force applying on the poles through the conductors can be calculated by Eq (2), which is provided by Ausgrid.

$$
W_{T}=0.5 L d P C F_{S R} \cos ^{2} \alpha
$$


where $W_{T}$ is the transverse force applied to the pole due to conductor windage, $L$ denotes the span length, $d$ is the projected diameter of conductor, $P$ is the design wind pressure on conductor, $C$ is the drag coefficient of conductor, $F_{S R}$ is the span reduction factor and $\alpha$ represents the angle between wind direction and normal to the conductor.

Besides, the maximum span length was set to $80 \mathrm{~m}$ (typical length of $65 \mathrm{~m}$ ) in this study for the main application in the urban area. In this case, the SRF can be ignored as the span lengths tended to be short. For the urban area, wind pressure of $900 \mathrm{~Pa}$ is widely utilized by the industry for distribution line design and drag coefficient is always set as 1.16. Suppose the wind direction is normal to the conductors, the angle $\alpha$ shall be 0 and the value of $\cos ^{2} \alpha$ shall be 1 . In this situation, $W_{T}$ depends on the model of the conductors or the cables.

Conductor low voltage aerial bundled cable (LVABC) $95 \mathrm{~mm}^{2}$ is normally used in residential areas. It is a preferred cable type for new low voltage mains and unsuitable for long spans, so this cable is typically used in the urban area for distribution application. One or two cables can be attached to the utility poles for network distribution, and one cable attached is normally used in residential areas and were considered in this study. For the straight line intermediate situation (See Fig. 1), the maximum wind load on the LVABC is $2.62 \mathrm{kN}$ according to Ausgrid NS220. This value covers the majority of situations except the situation of extremely long span and includes the ultimate limit state.

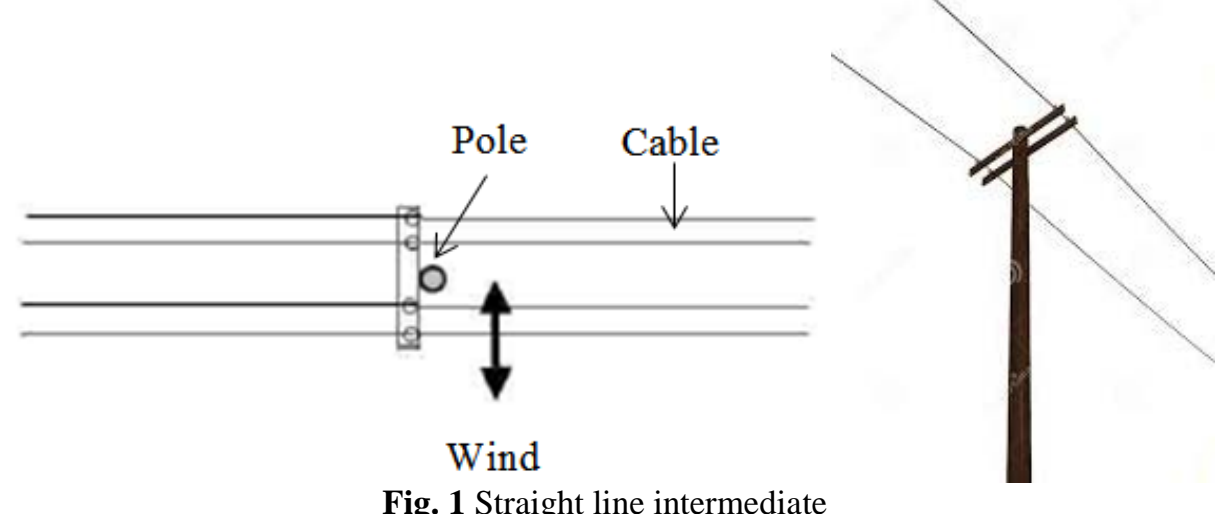

As a consequence, the total wind load applied on network distribution can be calculated, the value of which is $4.57 \mathrm{kN}$.

\section{Load capacity analysis of timber poles under wind loading}

According to Australia Standard AS1720.1 [4], the load capacity design is mainly based on modifying the characteristic capacities by factors approximate to the service condition as well as the material property type [6]. The design capacity in bending of round timber structures such as poles or piles for the strength limit state has to satisfy the following relationships as stated in AS1720.1 [4] :

$$
\begin{gathered}
\mathrm{M}_{\mathrm{d}} \geq \mathrm{M}^{*} \\
\mathrm{M}_{\mathrm{d}}=\emptyset \mathrm{k}_{1} \mathrm{k}_{4} \mathrm{k}_{6} \mathrm{k}_{9} \mathrm{k}_{12} \mathrm{k}_{20} \mathrm{k}_{21} \mathrm{k}_{22} \mathrm{f}_{\mathrm{b}}^{\prime} \mathrm{Z}
\end{gathered}
$$

where $M^{*}$ indicates bending generated by strength limit state design load; $\phi$ represents the capacity factor with the value of 0.6 for round timber intended to fulfil an essential service; $k_{1}$ to $k_{9}$ denote the strength modification factors; $k_{1}$ indicates the effect of the load duration and is set to 1.0 when considering extreme wind load; $k_{4}$ is the moisture condition and equals 1.0 for unseasoned timber such as utility pole structures; $k_{6}$ is the temperature factor and is set to 1.0 for Sydney region; $k_{9}$ is the strength-sharing factor and equals 1.0 for the discrete parallel system such utility poles; $k_{12}$ is the stability factor with the value of 1.0 for round timber; $k_{20}$ represents the immaturity factor with the value of 1.0 for hardwood with mid-length diameter greater than $0.125 \mathrm{~m} ; k_{21}$ is the shaving factor with the value of 0.85 for hardwood considering bending strength; $k_{22}$ is the processing factor - if the poles are steamed, its value is 0.85 , or else it shall be $1.0 ; \mathrm{f}_{\mathrm{b}}^{\prime}$ stands for the characteristic strength in 
bending, which can be evaluated by in-grade testing; $\mathrm{Z}$ is the section modulus of a round timber with the following expression:

$$
\mathrm{Z}=\frac{\pi \mathrm{d}_{\mathrm{p}}^{3}}{32}
$$

where $d_{p}$ is the diameter of the pole at the corresponding section.

The main limitation of this criterion is that it does not consider the influences of the damage type of a timber pole on its strength performance. Suppose there are two types of damage and both of them cause the same loss of cross-section but one of the damages is on the surface and the other is internal. In this case, the calculated section modulus $(Z)$ of the two damage scenarios as well as the bending capacity will be the same. However, the effects caused by these two types of damage are distinctly different. Ausgrid Standard NS220 highlights this difference based on the following equations:

$$
\begin{gathered}
\mathrm{F}_{\mathrm{T}}=\frac{\mathrm{kf}_{\mathrm{b}}^{\prime} \pi \mathrm{D}^{3}}{32 \mathrm{~h}} \times 1000 \\
\mathrm{~F}_{\mathrm{T}}=\frac{\mathrm{kf}_{\mathrm{b}}^{\prime} \pi\left(\mathrm{D}^{4}-\mathrm{d}^{4}\right)}{32 \mathrm{hD}} \times 1000
\end{gathered}
$$

where $F_{T}$ shows the ultimate tip strength; $D$ and $d$ are diameters of ground line and internal hollow, respectively; $h$ is the tip height above ground; $k$ is a factor accounting for load duration, degradation, shaving, immaturity and processing, and its value is 0.8 for assessment of in-service poles. Following NS220 [7], Eq. (6) is used to calculate the tip strength of a pole if there is an external damage at the ground level while Eq. (7) is used for an internal damage scenario. To determine the actual strength of the timber pole, the code of practice defined in NS220 [7] primarily evaluates the tip load capacity instead of the bending capacity used in other studies.

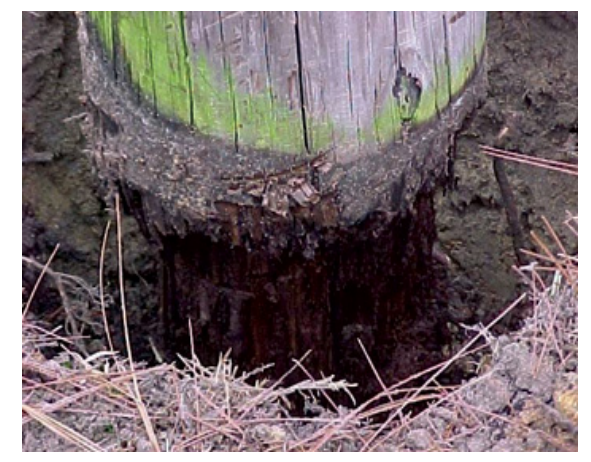

Fig. 2 Typical example of external ground line decay

Eqs. (6) and (7) mainly represent damage that is located at the ground level (see Fig. 2) and indeed, in practice, damage is more likely to occur at the ground level than any other area and its effects can have severe consequences. Therefore, for practical applications, it is reasonable to concentrate on the study of the influence of ground level damage to the pole strength. For in-depth research, however, this study also investigates the influence caused by other damage locations.

\section{Strength analysis of damaged timber poles}

\subsection{Numerical modeling of timber poles}

For the strength analysis study, a number of finite element models of timber poles with different damage scenarios are generated to investigate the influence of the damage type to the pole strength. The following damage scenarios are investigated: 1) two damage types are considered: external and internal damages; 2) three positions of damage are considered: ground level, middle and top areas ( $2 \mathrm{~m}$ from the top of the pole); 3) five types of damage severities are considered; 4) five types of damage length are considered. 
Numerical models were created by ANSYS using element SOLID 185 and the length of element size is $50 \mathrm{~mm}$. According to [8], the material properties for the timber pole are defined as $23,000 \mathrm{MPa}$ of Elastic modulus and 0.3 of Poison's ratio. The density for three different types of models is set to $950 \mathrm{~kg} / \mathrm{m}^{3}$. Besides, the lateral capacity is determined by the poles and the interaction between pole and soil. The ability of the pole to resist lateral loads, such as wind loads, depends on the pole dimension, material and the soil properties as well as bracing. The soil characteristics, their location on the site and their compressive strength can influence the capacity of site soils to resist lateral loads, which have been considered by the design standard of utility poles. According to Ausgrid Standard NS 220, the timber poles for power distribution in the urban area are normally LV poles with $12 \mathrm{~m}$ long and the embedment depth is considered as $1.5 \mathrm{~m}$ to $2 \mathrm{~m}$ for the area consisting of relatively hard upper strata of sandstone.

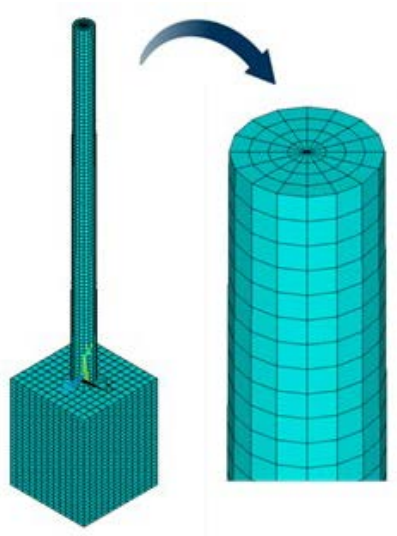

Fig. 3 3D finite element model for timber pole with orthotropic material

In this study, transverse wind load is the main source of loading on the pole. Therefore, 2D axisymmetric modelling is not adequate, and thus 3D orthotropic material models are generated, shown in Fig. 3. Fig. 4 shows the different damage types and locations. To obtain the strength in bending for the pole under the wind load, the maximum strength in the longitudinal direction of the pole is determined. The determined maximum strength in bending under wind loading is subsequently used to evaluate the influence of different damage scenarios on the strength of the poles. The applied wind load was given in the last section according to Ausgrid Standard NS220 [7]. 


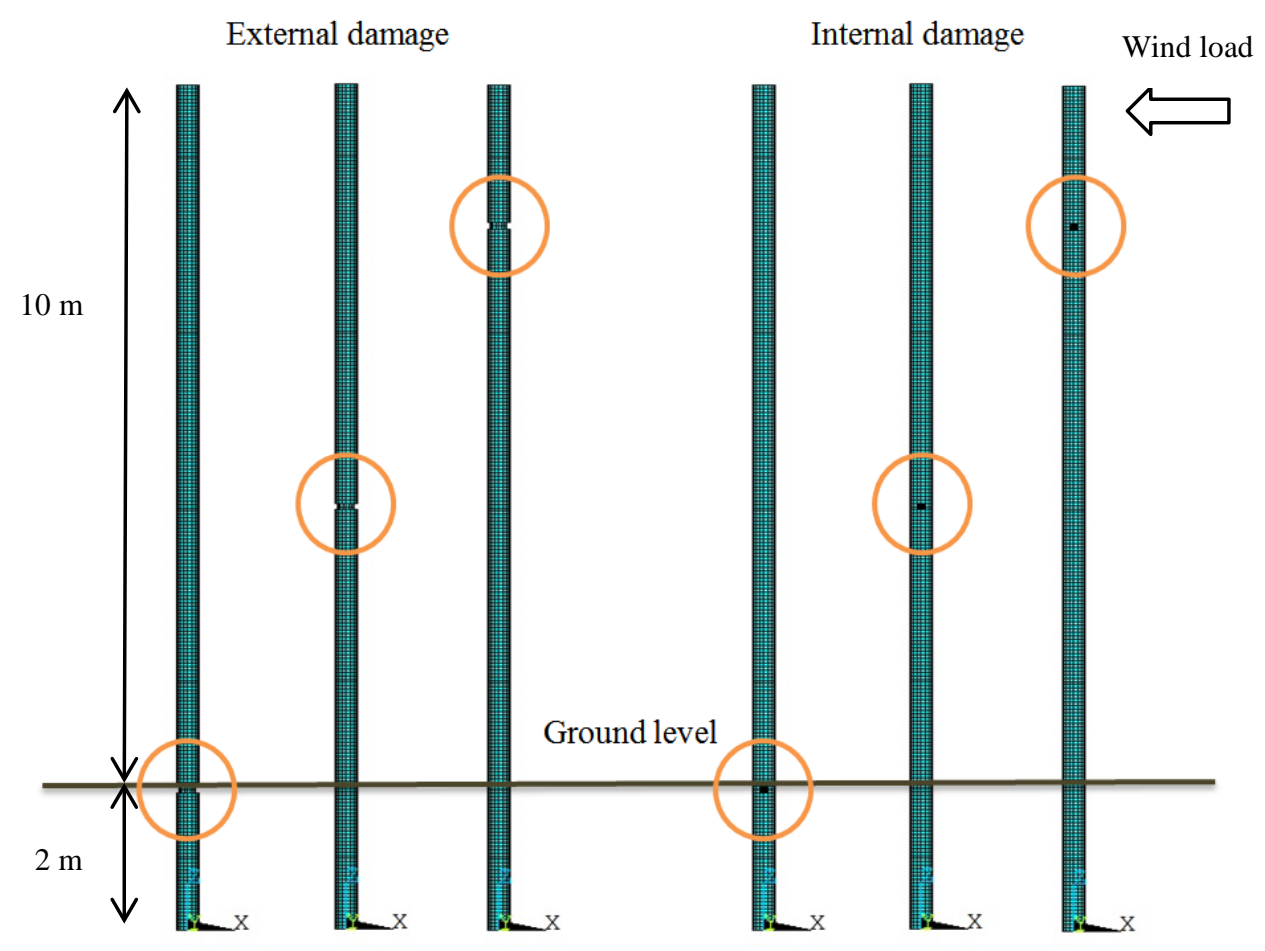

Fig. 4 Different damage types and locations

For this study, the numerically generated timber poles are made of hardwood of the species Spotted Gum (Eucalyptus Maculate). According to AS1720.1 and Ausgrid Standard, Spotted Gum with unseasoned condition is in the list of strength group S2, which represents common timber utility poles used in Australia. The characteristic strength in bending according to AS2209 is $80 \mathrm{MPa}$ and the value of 0.8 for assessing an in-service pole is normally used accounting for load duration, degradation, shaving, immaturity and processing. The strength factor of wood poles is normally set as 0.6. And thus, the ultimate strength limit in bending of $38 \mathrm{MPa}$ can be calculated by multiplying these three factors.

In the numerical static analysis, the wind load is applied to the various timber poles (inflicted with different types of damage) and the maximum strength in bending is obtained. The safety ratio $R_{S}$ is employed to determine the damage effects on the strength of a pole. $R_{S}$ is expressed as:

$$
R_{S}=\frac{\text { Obtained bending strength }}{\text { Ultimate designed strength }}
$$

First, the strength of the intact pole under the wind load is determined. The corresponding results are shown in Table 2, which lists the maximum strength in bending for the intact pole with specific dimension under the wind load. The wind load considered here includes the wind load acting on the pole as well as loading from the attached cables. It can be seen that the maximum strength caused by wind load is much less than the ultimate design strength, and the calculated safety ratio of 0.42 indicates that the pole is safe under the wind load.

Table 2 Strength analysis of an intact pole ( $L$ : pole length, $D$ : pole average diameter, $R_{s}$ : safety ratio)

\begin{tabular}{ccccc}
\hline \multicolumn{5}{c}{ Ultimate design strength in bending: 38 MPa } \\
\hline$L(\mathrm{~m})$ & $D(\mathrm{~mm})$ & Wind load $(\mathrm{kN})$ & Max. strength in bending $(\mathrm{MPa})$ & $R_{s}$ \\
12 & 315 & 4.57 & 16.82 & $42 \%$ \\
\hline
\end{tabular}




\subsection{Damage at ground level of timber pole}

As mentioned above, damage near the ground level is most likely to happen and will significantly influence the load capacity of a utility pole. Table 3 lists the damage specifications and calculated acceptable tip load of timber utility poles for the intact pole as well as various poles damaged at ground level following Eqs. (6) and (7). From Table 2, it can be seen that for a timber pole with small external damage such as a damage width of $79 \mathrm{~mm}$ at the ground position, the calculated tip load capacity is greater than the wind load, which means that the damaged pole still has a reasonably safe load capacity under service condition. However, a pole with a larger external damage on the surface at the ground level can result in a significant loss of the pole load carrying capacity. As for the internal damage condition, a pole can still have a sufficient load capacity even when a large internal damage is present. It is noted that the load capacity of a pole with large internal damage $(236 \mathrm{~mm})$ is almost twice that of a pole with small external damage $(79 \mathrm{~mm})$. With this comparative analysis, it can be seen that external damage at ground level influences the load capacity of a utility pole significantly.

Table 3 Maximum acceptable tip loads for intact pole and poles damaged at ground level

\begin{tabular}{ccccc}
\hline \multicolumn{2}{c}{ External damage pole } & \multicolumn{2}{c}{ Internal damage pole } & Intact pole \\
\hline$W_{D}(\mathrm{~mm})$ & $F_{T}(\mathrm{kN})$ & $d(\mathrm{~mm})$ & $F_{T}(\mathrm{kN})$ & $F_{T}(\mathrm{kN})$ \\
79 & 4.90 & 79 & 11.61 & \\
118 & 2.85 & 118 & 11.43 & \\
158 & 1.44 & 158 & 10.92 & 11.66 \\
197 & 0.61 & 197 & 9.88 & \\
236 & 0.18 & 236 & 7.99 & \\
\hline
\end{tabular}

$W_{D}$ and $d$ are the diameters of the external and internal damaged parts, and $F_{T}$ indicates the ultimate tip strength.

In addition to the study of damage of varying diameters, also a damage severity study with damage of different diameters and lengths was undertaken for external and internal damage at the critical ground level position. From the results of the numerical analysis presented in Table 4, a similar phenomenon to the one described above is observed. In Table $4, R_{L}$ and $R_{W}$ is the proportions of length and diameter of the damaged part to the original dimension, respectively. For small external damage, the utility pole still has considerable bending strength under the wind load. However, the maximum bending strength of the damaged pole is close to the ultimate designed strength under the wind load. With an increasing damage size, the maximum bending strength on the pole under the wind load will exceed the ultimate bending strength and accordingly cause collapse. The results from Table 4 also indicate that under small damage size, the damage length does not influence on the bending strength of the pole significantly. However, when the damage size increases, the influence of the damage length will be more obviously and this will be discussed later in the paper.

Table 4 Influence of external light damage at ground level to the strength of a pole

\begin{tabular}{ccccccc}
\hline \multicolumn{6}{c}{$L=12 \mathrm{~m}, D=315 \mathrm{~mm}$, Ultimate designed strength in bending: 38MPa } \\
\hline \multirow{2}{*}{$W_{D}(\mathrm{~mm})$} & $L_{D}(\mathrm{~mm})$ & $R_{L}=L_{D} / L$ & $R_{W}=W_{D} / D$ & Max. Load $(\mathrm{kN})$ & $\begin{array}{c}\text { Max. Strength } \\
(\mathrm{MPa})\end{array}$ & $R_{s}$ \\
\hline \multirow{4}{*}{79} & 100 & $1 \%$ & $25 \%$ & & 34.83 & $92 \%$ \\
& 200 & $2 \%$ & $25 \%$ & 4.57 & 35.11 & $92 \%$ \\
& 300 & $3 \%$ & $25 \%$ & & 35.28 & $92 \%$ \\
& 400 & $4 \%$ & $25 \%$ & 35.42 & $92 \%$ \\
& 500 & $5 \%$ & $25 \%$ & & 35.74 & $95 \%$ \\
\hline
\end{tabular}

Note: $L$ is the length of the pole, $L_{D}$ represents the length of damaged part, $D$ is the mean diameter of the pole, and $W_{D}$ shows the diameter of the external damaged part.

Table 5 lists the determined strength parameters of the poles with internal damage occurring at the ground level under the wind load. It can be seen that even if the damage severity reaches $75 \%$ of the original diameter, the maximum strength in bending is still smaller than the ultimate designed strength. Consequently, internal damage has much less influence on the strength of the pole within a certain range. Another issue which should be highlighted is the influence of the damage length. While the 
diameter/width of damage remains the most important factor on the strength of a pole, the influence of the damage length to the remaining strength of utility poles should not be neglected, as it is the case for the existing Australian Standard AS1720.1 [4], which does not take into account the length of damage. From Table 4, it can be seen that with the increase of the damage diameter, the length of the damage becomes more significant in affecting the bending strength of a pole. For instance, the safety ratio is $52 \%$ for a damage dimension of $236 \mathrm{~mm} \times 100 \mathrm{~mm}$ while the ratio increases to $70 \%$ for a damage dimension of $236 \mathrm{~mm} \times 500 \mathrm{~mm}$.

Table 5 Influences of internal damage at ground level to the strength of a pole

\begin{tabular}{|c|c|c|c|c|c|c|}
\hline \multicolumn{7}{|c|}{$\begin{array}{c}L=12 \mathrm{~m}, D=315 \mathrm{~mm} \text {, ultimate designed strength in bending: 38MPa, maximum accepted wind load: } \\
11.66 \mathrm{kN}\end{array}$} \\
\hline$d(\mathrm{~mm})$ & $L_{D}(\mathrm{~mm})$ & $R_{L}=L_{D} / L$ & $R_{W}=d / D$ & Max. Load (kN) & $\begin{array}{l}\text { Max. Strength } \\
(\mathrm{MPa})\end{array}$ & $R_{s}$ \\
\hline \multirow{5}{*}{79} & 100 & $1 \%$ & $25 \%$ & \multirow{5}{*}{4.57} & 16.79 & $44 \%$ \\
\hline & 200 & $2 \%$ & $25 \%$ & & 16.92 & $44 \%$ \\
\hline & 300 & $3 \%$ & $25 \%$ & & 17.12 & $44 \%$ \\
\hline & 400 & $4 \%$ & $25 \%$ & & 17.25 & $44 \%$ \\
\hline & 500 & $5 \%$ & $25 \%$ & & 17.38 & $44 \%$ \\
\hline \multirow{5}{*}{236} & 100 & $1 \%$ & $37 \%$ & \multirow{5}{*}{4.57} & 20.75 & $52 \%$ \\
\hline & 200 & $2 \%$ & $37 \%$ & & 22.44 & $57 \%$ \\
\hline & 300 & $3 \%$ & $37 \%$ & & 25.19 & $65 \%$ \\
\hline & 400 & $4 \%$ & $37 \%$ & & 26.73 & $68 \%$ \\
\hline & 500 & $5 \%$ & $37 \%$ & & 27.62 & $70 \%$ \\
\hline
\end{tabular}

From the comparison of the strength results of external and internal damage from Tables 4 and 5, it can be seen that an external damage exceeding $25 \%$ of the original diameter of the pole will lead to collapse, while a utility pole can still be safe even if $75 \%$ of the internal cross section is lost. This observation highlights the important difference of strength influences of poles with external and internal damages.

Next, the remaining load capacity is investigated when damage occurs externally at the ground level. Here, the rate of maximum load capacity (LCR) is employed to evaluate the remaining load capacity according to the following equation:

$$
L C R=\frac{\text { Maximal load capacity of damaged pole }}{\text { Maximal load capacity of intact pole }}
$$

where the maximum load capacity is determined from the ultimate designed strength in bending which is $38 \mathrm{MPa}$; that is, to reach its maximum strength, the specified maximum load can be applied on the pole. Table 6 summarizes the remaining load capacity for the investigated poles with external damage at ground level. It can be seen that when arriving at the maximum bending strength, the intact pole is capable of carrying a maximum wind load of around $11.66 \mathrm{kN}$. The poles with damage size of $79 \mathrm{~mm}$ are able to be subjected to a maximum wind load of $4.8 \mathrm{kN}$. Even if this value is still higher than the wind load of $4.57 \mathrm{kN}$, the load capacity reduces to $44 \%$ compared to the intact pole. Moreover, from Table 6, a pole with a damage diameter of $118 \mathrm{~mm}$ is not able to carry the wind load of $4.57 \mathrm{kN}$. Here, the wind load includes the wind action on the pole as well as on the low voltage aerial bundled cable (LVABC) model, shown in Fig. 5 (a). It is noticeable that a pole with a damage size of $118 \mathrm{~mm}$ is unsafe to support this cable model under the designed wind speed. Another cable model (AAC-LV MERCURY 7/4.50), shown in Fig. 5 (b), is sometimes used where LVABC is unsuitable, especially for long span distribution and is also used for existing mains repairing. However, Ausgrid approval must be granted to use this bare conductor. According to these practical criteria, if LVABC is replaced by AAC-LV MERCURY 7/4.50, the wind load on the pole and cable is $2.87 \mathrm{kN}$, which is almost the maximum load capacity of a pole with a damage size of $118 \mathrm{~mm}$. Here, the load capacity declines to $25 \%$ of the intact pole. From this value, it can be seen that with a damage size reaching around one third of the original diameter of a pole, the load capacity reduces significantly. 
Table 6 Maximum load capacity for external damage at ground level

\begin{tabular}{cccccc}
\hline \multicolumn{6}{c}{$L=12 \mathrm{~m}, D=315 \mathrm{~mm}$, ultimate designed strength in bending: 38MPa, maximum accepted wind load: } \\
11.66kN \\
\hline$W_{D}(\mathrm{~mm})$ & $R_{W}=W_{D} / D$ & Max. Load $(\mathrm{kN})$ & $\begin{array}{c}\text { Max. Strength } \\
(\mathrm{MPa})\end{array}$ & $R_{S}$ & $L C R$ \\
\hline 79 & $25 \%$ & 4.8 & 36.74 & $97 \%$ & $44 \%$ \\
118 & $37 \%$ & 2.8 & 36.88 & $97 \%$ & $25 \%$ \\
158 & $50 \%$ & 1.4 & 37.05 & $97 \%$ & $13 \%$ \\
197 & $63 \%$ & 0.58 & 37.22 & $97 \%$ & $5 \%$ \\
236 & $75 \%$ & 0.175 & 37.39 & $97 \%$ & $1.6 \%$ \\
\hline
\end{tabular}

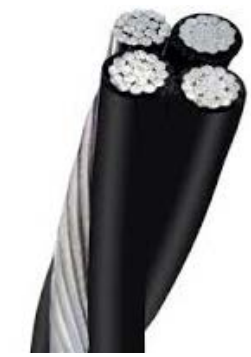

(a) LV ABC

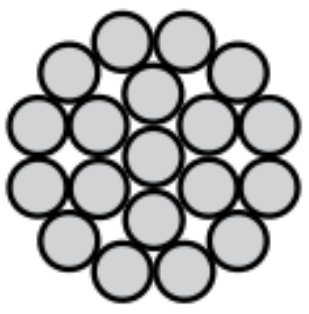

(b) AAC-LV MERCURY 7/4.50

Fig. 5 Cross-section of two common cables in Australia

For a pole with a damage size of $158 \mathrm{~mm}$, the maximum load capacity is $1.4 \mathrm{kN}$. This means the pole is not safe under the wind load even when there are no cable loading considered. However, this is unrealistic. In this case, poles with a damage size of $158 \mathrm{~mm}$ cannot be used in a network distribution application and the remaining load capacity is only 13\%. For larger damage sizes such as $197 \mathrm{~mm}$ and $236 \mathrm{~mm}$, the poles have lost almost their entire capacity of load bearing. Thus, according to these results based on numerical models, it can be concluded that for damage sizes greater than $25 \%$ of the original diameter of a pole, the damaged pole may be not safe for a distribution application.

Although the presence of internal damage (within a certain range) will not majorly affect the strength of a pole under the wind load, it is still valuable to analyse the maximum load capacity of a damaged pole under the ultimate designed bending strength. Table 7 presents the remaining load capacity for the poles with internal damage at the ground level. From the results, it can be found that the remaining load capacity does not decrease significantly even though half of the cross-section of the pole is lost. For poles with large-size damage, the remaining load capacity is above $60 \%$ of the intact condition.

However, it should be noted that the damage length studied in this research is up to $500 \mathrm{~mm}$. For light damage, such as $79 \mathrm{~mm}$, the length of the damage may not affect the strength significantly. On the other side, when the damage severity increases, the effect of damage length on the load capacity of a pole ascends dramatically, such as in the case of damage with a diameter of $236 \mathrm{~mm}$ presented in Table 8. With a small damage length, the bending strength is much smaller than the ultimate designed strength value. However, the maximum bending strength of a damaged pole almost reaches the ultimate designed strength when the damage length increases to $500 \mathrm{~mm}$.

Table 7 Maximum load capacity for internal damage at ground level

$L=12 \mathrm{~m}, D=315 \mathrm{~mm}$, ultimate designed strength in bending: 38MPa, maximum accepted wind load: $11.66 \mathrm{kN}$

\begin{tabular}{cccccc}
\hline$d(\mathrm{~mm})$ & $R_{W}=d / D$ & Max. Load $(\mathrm{kN})$ & $\begin{array}{c}\text { Max. Strength } \\
(\mathrm{MPa})\end{array}$ & $R_{s}$ & $L C R$ \\
\hline 79 & $25 \%$ & 10 & 36.77 & $97 \%$ & $98 \%$ \\
118 & $37 \%$ & 9.7 & 36.90 & $97 \%$ & $95 \%$ \\
158 & $50 \%$ & 9.3 & 37.09 & $97 \%$ & $91 \%$ \\
197 & $63 \%$ & 8.2 & 37.25 & $97 \%$ & $80 \%$ \\
236 & $75 \%$ & 6.4 & 37.37 & $97 \%$ & $63 \%$ \\
\hline
\end{tabular}


Table 8 Strength of poles with large damage

\begin{tabular}{cccccccc}
\hline$W_{D}(\mathrm{~mm})$ & $L_{D}(\mathrm{~mm})$ & $R_{L}=L_{D} / L$ & $R_{W}=W_{D} / D$ & Max. Load $(\mathrm{kN})$ & $\begin{array}{c}\text { Max. Strength } \\
(\mathrm{MPa})\end{array}$ & $R_{s}$ & $L C R$ \\
\hline \multirow{6}{*}{236} & 100 & $1 \%$ & $75 \%$ & & 28.34 & $80 \%$ \\
& 200 & $2 \%$ & $75 \%$ & & 31.45 & $95 \%$ & \\
& 300 & $3 \%$ & $75 \%$ & 6.4 & 35.20 & $97 \%$ & $63 \%$ \\
& 400 & $4 \%$ & $75 \%$ & & 36.18 & $97 \%$ & \\
\hline
\end{tabular}

Fig. 6 shows the maximum strength for five damage scenarios with different damage diameters and damage length, indicating the effect of damage length on the maximum bending strength of the poles under maximum load capacities. The figure shows that the maximum strength of a pole with small damage size $(79 \mathrm{~mm})$ is almost unaffected by the damage length, and thus, the mark points indicating the maximum bending strength under five different damage length scenarios are almost overlapped. When the damage size increases, the effect of damage length on the maximum strength becomes larger. For example, the damage size reaches $236 \mathrm{~mm}$, the damage length influence on the maximum bending strength of the pole is obviously different: the damage length of $100 \mathrm{~mm}$ causes maximum bending strength is around $28.34 \mathrm{MPa}$ while the damage length of $500 \mathrm{~mm}$ leads to a maximum bending strength of 37.38MPa.

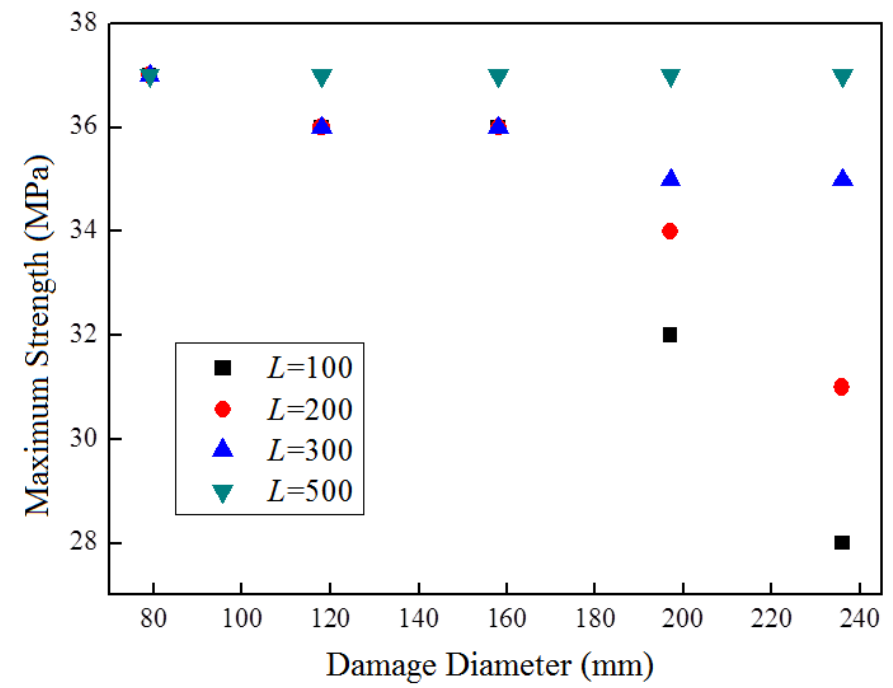

Fig. 6 Influences of damage diameter and length (external damage) on the maximum strength of timber poles.

Fig. 7 depicts the load capacity changes of external and internal damage due to increasing damage diameter. The solid curve represents the load capacity of the internal damage condition. It can be seen that the curve for the internal damage has a lower gradient compared to the curve of the external damage. Further, the maximum load capacity of utility poles with internal damage is larger than poles with external damage. For the internal damage situation, the load capacity only changes marginally for a damage size smaller than $150 \mathrm{~mm}$. However, with the damage size increasing, the load capacity declines significantly. For the external damage condition, the load capacity drops considerably for poles with increasing damage size.

Since in the presented load capacity study only transverse wind loads are considered, the pole structure can be regarded as a cantilever beam with the maximum strength being present at the bottom of the cantilever beam. Normal bending strength is of greatest concern for cantilever beams in bending. At any section of a cantilever beam, the fibre strength will be largest at the surface farthest away from the neutral axis (maximum bending strength). Such behaviour further support the fact that external damage plays a more critical role in affecting the bending strength as well as the remaining load capacity in utility poles. 


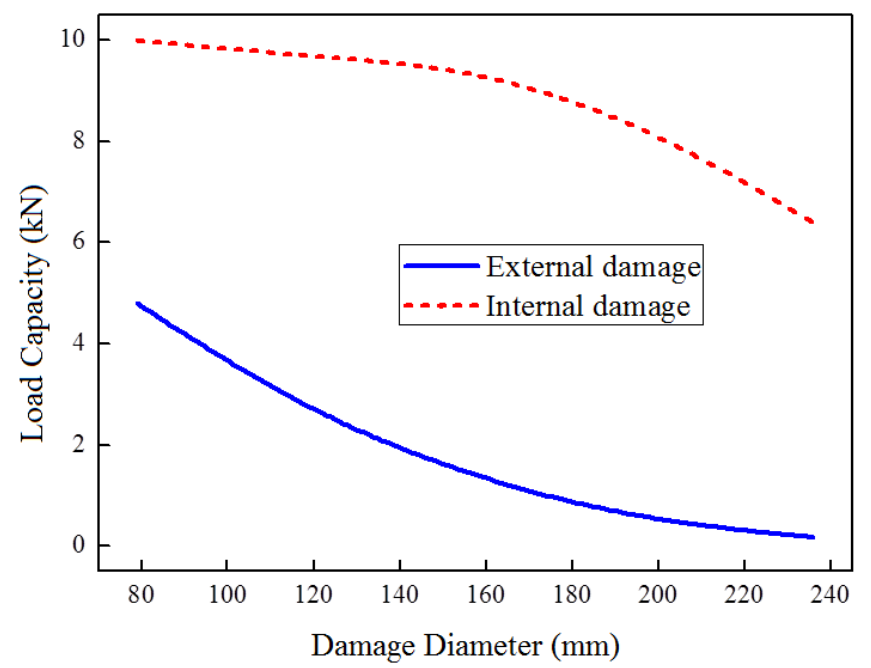

Fig. 7 Load capacity changes of external and internal damage due to increasing damage diameter.

\subsection{Damage at middle and top regions of timber pole}

This section investigates the influences of damage at middle and top areas of timber poles on their strength and load capacity properties. Again, numerical models are used to support this study; and the same damage scenarios as the above are investigated, that is, external and internal damage with different damage sizes and lengths. First, the maximum load capacities of externally damaged poles at the middle region (4 m above ground) of utility poles are calculated based on numerical static analysis - the corresponding results are listed in Table 9. From the results it can be seen that even with damage at the middle of the pole, external damage significantly affects the load capacity of a pole. For light damage, such as of damage size $79 \mathrm{~mm}$, the maximum load capacity is $5.3 \mathrm{kN}$ and slightly higher than the load capacity of a pole which has the same damage size at the ground level. When the damage size reaches one third of the original diameter of a pole, it is be noted that the load capacity is smaller than the wind load. In such case, the damaged pole cannot carry the LVABC. Poles with medium and large damage sizes have almost lost their entire load capacity. These results indicate that external damage at ground level and at the middle section of a pole have similar influences on the bending strength of timber utility poles.

Table 9 Maximum load capacity for external damage at the middle region of a pole

\begin{tabular}{cccccc}
\hline \multicolumn{6}{c}{$L=12 \mathrm{~m}, D=315 \mathrm{~mm}$, ultimate designed strength in bending: 38MPa, maximum accepted wind load: } \\
\hline \multicolumn{6}{c}{$11.66 \mathrm{kN}$} \\
$W_{D}(\mathrm{~mm})$ & $R_{W}=W_{D} / D$ & Max. Load $(\mathrm{kN})$ & $\begin{array}{c}\text { Max. Strength } \\
(\mathrm{MPa})\end{array}$ & $R_{s}$ & $L C R$ \\
\hline 79 & $25 \%$ & 5.3 & 36.76 & $97 \%$ & $64 \%$ \\
118 & $37 \%$ & 3.3 & 36.90 & $97 \%$ & $39 \%$ \\
158 & $50 \%$ & 1.8 & 37.06 & $97 \%$ & $19.5 \%$ \\
197 & $63 \%$ & 0.83 & 37.19 & $97 \%$ & $8.6 \%$ \\
236 & $75 \%$ & 0.23 & 37.32 & $97 \%$ & $2.6 \%$ \\
\hline
\end{tabular}

The maximum load capacity for external damage at the top area ( $2 \mathrm{~m}$ below the top) of a pole is also investigated using numerical analysis and the summarized results are shown in Table 10. It can be seen that the load capacity of poles with a damage size of $79 \mathrm{~mm}$ and $118 \mathrm{~mm}$ at the top area is not influenced much. Although the load capacity decreases dramatically when the damage size increases to $158 \mathrm{~mm}$, the damaged pole does still have sufficient capacity to carry the wind load. However, for larger damage size of $236 \mathrm{~mm}$, the damaged pole has almost lost its entire load capacity under the wind load.

Table 10 Maximum load capacity for external damage at the top of a pole 


\begin{tabular}{cccccc}
\hline \multicolumn{6}{c}{$L=12 \mathrm{~m}, D=315 \mathrm{~mm}$, ultimate designed strength in bending: 38MPa, maximum accepted wind load: } \\
$11.66 \mathrm{kN}$
\end{tabular}

Based on the above results, it can be concluded that any large-size external damage significantly influences the bending strength of utility poles regardless of the damage position. Poles with light damage have sufficient strength to carry the wind load even though the maximum load capacity of the pole is still influenced. However, whether a pole with medium-size damage can carry the design wind load depends on the damage location. Fig. 8 illustrates that the maximum load capacity of a pole with external damage at the ground level is similar to a pole with external damage at the middle region. The maximum load capacity for poles with light or medium external damage at the top area is much larger than the same damage at the ground level or in the middle section. A large external damage, such as a damage size of $236 \mathrm{~mm}$, leads to the total loss of the load capacity.

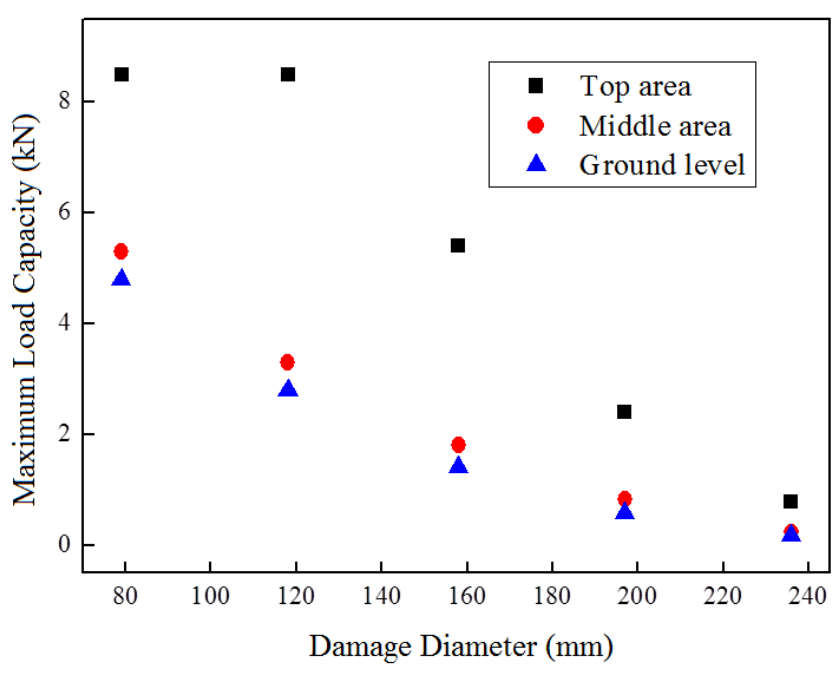

Fig. 8 Maximum load capacities of utility poles with external damage at different locations

The maximum load capacity for internal damage at the middle and top areas of utility poles are also analysed for the same damage sizes. It is found that the maximum load capacity will only marginally be influenced by whether the internal damage occurs at the middle or at the top area. The maximum bending strength of poles with internal damage at the middle or the top area is almost the same as for the intact pole. Hence, internal damage at the middle or the top area of a pole will only have a very minor effect on the maximum bending strength as well as the load capacity of a pole. As it was mentioned previously, at any section of a cantilever beam, the fibre strength will be largest at the surface farthest away from the neutral axis (maximum bending strength). For the external damage on the pole, the maximum stress occurs at the damage area. Although the presence of internal damage (within a certain range) will not majorly affect the strength of a pole under the wind load, the maximum stress always occurs at the ground level no matter where the damage location is.

\section{Conclusion}

This paper presented a numerical investigation on the influence of damage of different locations and severities on the load capacity of timber utility poles. In practical industry applications, pole damage is generally divided into two types: external and internal damage. The presented numerical analysis demonstrated that external damage significantly reduces the load capacity of a timber pole while 
internal damage only results in a small loss of the load capacity within a certain range. Under design wind loading, a pole with mid- to large-size external damage has a high possibility of collapse due to the damage while a pole with internal damage will still have large strength capacities. It is noted that cables attached to a pole also play a significant role in determining the load capacity of the pole under the wind load. An external damage at ground level is the most serious damage scenario to affect the load capacity of a timber pole. Internal damage at ground level has significantly less influence on the pole strength compared to external damage. All bending strength and load capacity results are calculated based on Australian Standards and Ausgrid Manuals, which provide theoretical guidance on the design and condition assessment in the pole management industry.

\section{Acknowledgement}

This research was supported by the Australian Research Council and Ausgrid through the Linkage Project (LP110200162). The authors are also thankful to the editor and anonymous reviewers for their constructive comments.

\section{Reference}

1. Nguyen M, Foliente G, Wang X (2004) State of the practice \& challenges in non-destructive evaluation of utility poles in service. Key Engineering Materials - Advances in non-destructive evaluation 270-273:1521-1528 2. Crews KI, Horrigan A (2000) Strength assessment of timber utility poles in Australia. New Zealand Timber Design Journal 9 (2)

3. Holmes JD (2001) Wind Loading of Structures. Spon Press, London

4. Australian Standard (2010) AS1720.1 - Timber structures - Part 1: Design methods.

5. Francis L, Norton J (2006) Australian timber pole resources for energy networks - a review. Department of Primary Industries \& Fisheries, Queensland

6. Ausgrid (2011) Network Standard NS 145, Pole Inspection and Treatment Procedures.

7. Ausgrid (2015) Network Standard NS 220. Overhead Design Manual, NW000-S0092.

8. Bootle KR (1983) Wood in Australia, Australia, MaGraw-Hill Australia Pty Ltd. 